\title{
Strongyloides stercoralis associated with a bleeding gastric ulcer
}

\author{
A Dees, P L Batenburg, H M Umar, R S Menon, J Verweij
}

Departments of Medical Oncology and Pathology, Rotterdam Cancer Institute/Daniel den

Hoed Kliniek,

Rotterdam, The

Netherlands

A Dees

H M Umar

R S Menon

J Verweij

Department of Medicine,

Zuiderziekenhuis,

Rotterdam, The

Netherlands

P L Batenburg

Correspondence to:

Dr A Dees, Department of

Medical Oncology, Rotterdam

Cancer Institute/Daniel den

Hoed Kliniek, PO Box 5201

3008 AE Rotterdam, The

Netherlands.

2 February 1990
Accepted for publication

\begin{abstract}
Infection with the helminthic parasite, Strongyloides stercoralis, is usually acquired by skin invasion (or occasionally via ingestion of larvae). After transformation to the adult form, the parasite preferentially localises in the small intestine, especially in the duodenal and jejunal part. ${ }^{1} A$ remarkable feature of Strongyloides is its property of endogenous reinfection. In the case of an immunocompromised host a massive infection, called hyperinfections Strongyloides, may occur. ${ }^{23}$ Numerous gastrointestinal complications of strongyloides infections, sometimes with a lethal outcome, have been reported. ${ }^{4}$ The intestinal manifestations are usually limited to the small bowel, and rarely involve the stomach. We report a patient with complicated strongyloides infection of the stomach.
\end{abstract}

\section{Case report}

A 70 year old man was admitted to hospital with angina pectoris and hypotension. He had a history of myocardial infarction 11 and 8 years earlier, and a thrombotic cerebrovascular accident three years previously. At that time he was treated with anticoagulants. The medical history also showed mild hypertension and chronic bronchitis. He had been a heavy smoker

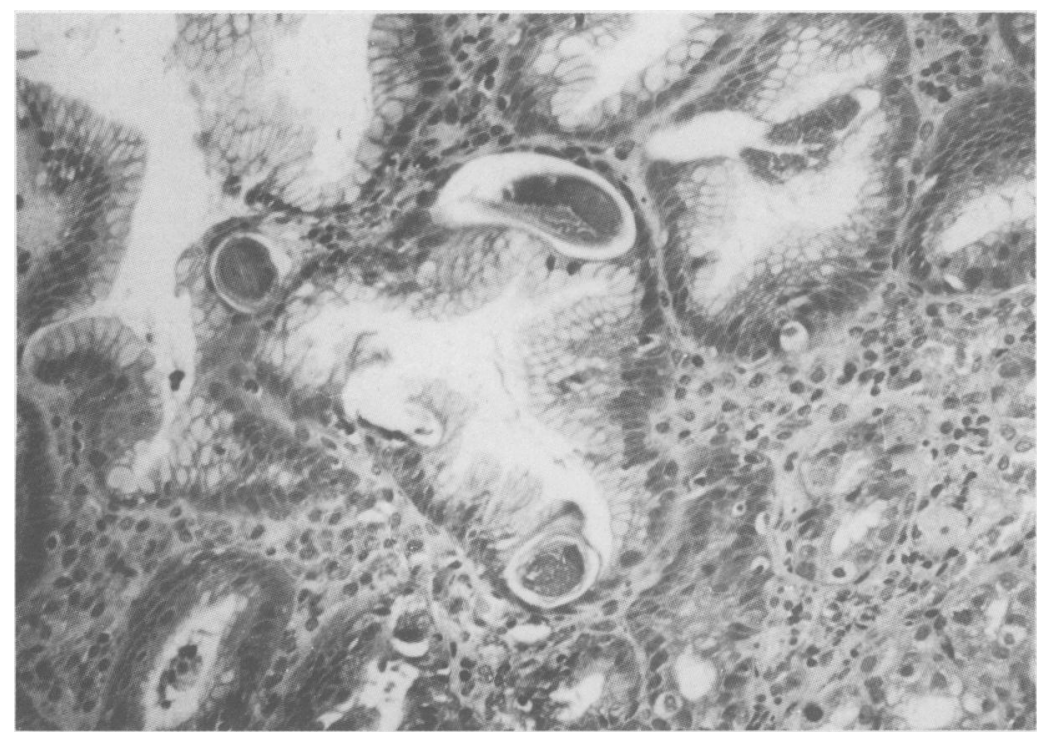

Figure 1: Haematoxylin-eosin stained section of gastric biopsy specimen showing eggs and larvae deep within the mucosa (original magnification $\times 250$.)

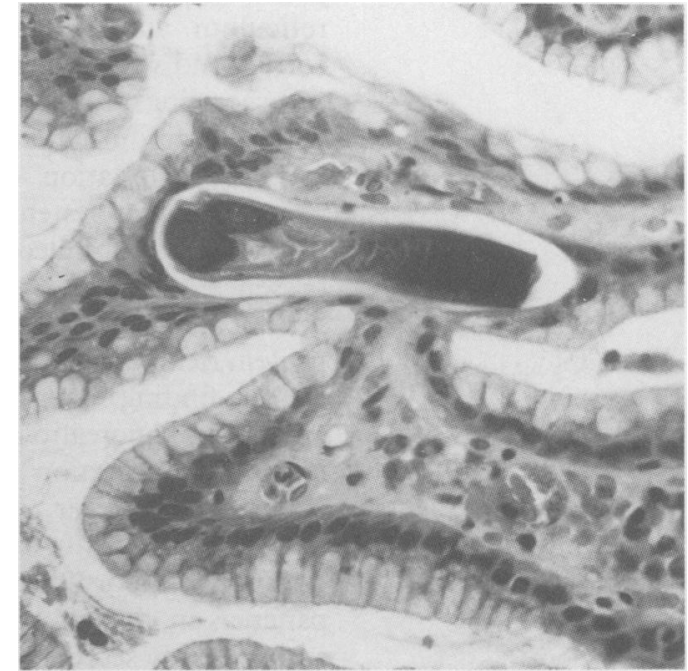

Figure 2: Gastric mucosa (original magnification $\times 400$ ) showing adult form of Strongyloides stercoralis

for many years and was a former World War II prisoner on the Burma railroad, where he experienced several attacks of malaria.

Three months before hospital admission, a large tumour of the oral cavity, stage $\mathrm{T}_{3} \mathrm{~N}_{0} \mathrm{M}_{0}$ according to the UICC classification, was diagnosed and radiation therapy was given at a total dose of $40 \mathrm{~Gy}$.

On admission, there was a history of high fever, diarrhoea, and weight loss of $8 \mathrm{~kg}$ over three weeks. No signs of ulcer disease or genitourinary tract disease were noted. On examination there was pallor, the temperature was $38.5^{\circ} \mathrm{C}$ and the blood pressure was $90 / 50 \mathrm{mmHg}$. Heart and lungs were normal, except for a systolic murmur. On rectal examination, melaena was noticed. An electrocardiogram showed sinus rhythm and marked S-T segment depression in the lateral leads. The haemoglobin concentration was 3.3 $\mathrm{mmol} / \mathrm{l}$ and the white blood cell count was $7800 /$ $\mathrm{mm}^{3}$ with $7 \%$ eosinophils, $5 \%$ bandforms, $73 \%$ neutrophils, 7\% lymphocytes, and 7\% monocytes. The platelet count, electrolytes, renal function, bilirubin, and liver enzyme values were all normal. Cultures from blood and urine were negative, as were the investigations of stool specimen for parasite eggs or larvae.

The patient was treated with 6 units of packed red blood cells, and antibiotics plus $\mathrm{H}_{2}$ receptor antagonists were administered intravenously. After recovery an upper endoscopy was performed. A large prepyloric ulcer with signs of 
recent bleeding was found and biopsy specimens were taken. On microscopical examination the ulcer proved to be non-malignant, but mucosal crypts and luminae were infiltrated by helminthic eggs and larvae (Figs 1 and 2). A course of 50 $\mathrm{mg} / \mathrm{kg}$ tiabendazole was given for three days. He was discharged from hospital and a second endoscopy was performed three weeks later. Surprisingly, multiple small white lesions were observed in the upper oesophagus, while the gastric ulcer had healed. Histology of the lesions showed differentiated squamous carcinoma. Two months later the patient died of metastatic disease.

\section{Discussion}

Strongyloides stercoralis is a common helminthic parasite in (sub)tropical areas. After infection of the host, the parasite can persist for decades. ${ }^{5}$ Hyperinfection strongyloides usually occurs only in cases of severe immunosuppression due to malignancy, starvation, or the use of immunosuppressive drugs such as corticosteroids. In these patients the infection can easily be overlooked, especially in those with concomitant yeast or bacterial sepsis. Igra-Siegman et al, reviewed more than 100 cases of hyperinfection and noticed that $89 \%$ of patients were immunocompromised, while $86 \%$ died shortly afterwards. ${ }^{6}$ An immunosuppressive state presumably also contributed to complicated strongyloides infection in our patient, since both the squamous cell carcinoma and the radiation therapy would have suppressed the immune system. ${ }^{7}$ Secondary sepsis often contributes to a lethal outcome in an immunocompromised host with hyperinfection strongyloides. In about $30 \%$ of these patients the diagnosis was only made at necropsy. ${ }^{6}$
As in our patient, the initial gastrointestinal symptoms are often unspecific, but later severe complications like bleeding, mechanical ileus, or bowel perforation can occur. Prolonged infection usually affects the small bowel, and can cause mucous production, superficial haemorrhage, and even fibrosis, mimicking inflammatory bowel disease. ${ }^{8}$

The gastric localisation in our patient underlines the fact that infection is not always limited to the small bowel. Of course, the key question remains whether $S$ stercoralis was the cause of the ulcer, or whether the ulcer was secondarily infected with larvae. In patients presenting with fever, mild or transient eosinophilia, and ulcer bleeding, strongyloides infection should be considered, in particular when clues for diagnosis can be found in the patient's past medical history.

Acknowledgment to Mrs Jacqueline Dito for typing and to Dr J Samut-Tagliaferro for reviewing the manuscript.

1 Spencer H. Tropical Pathology. In: Doerr W, Siefert G, Uehlinger E, eds. Spezielle pathologische anatomie. Berlin: Springer-Verlag, 1973; 8: 492-7.

2 Powel RW, Moss JP, Nagar D, et al. Strongyloides in immunosuppressed hosts. Arch Intern Med 1980; 140: 1061-3.

3 Cook GC. Strongyloides stercoralis hyperinfection syndrome, how often is it missed? Qf Med 1987; 64: 625-30.

4 De Paola D, Braga Dias L, Da Silva JR. Enteritis due to Strongyloides stercoralis: a report of 5 fatal cases. Am $\mathcal{F}$ Dig Dis
Sala 1962; 7: 1086-98.

5 Gill GV, Bell DR. Strongyloides stercoralis infection in former Far East Prisoners War. Br Med $\mathcal{F} 1979 ; 2: 572-4$.

6 Igra-Siegman Y, Kapila R, Sen P, Kaminski ZC, Louira DB. Syndrome of hyperinfection with Strongyloides stercoralis. Rev Infect Dis 1981; 3: 397-407.

7 Veltri RW, Rodman SM, Maxim PE, Baseler MW, Sprinkle PM. Immune complexes, serum proteins, cell-mediated immunity and immune regulation in patients with squamous cell carcinoma of the head and neck. Cancer 1986; 57: 2295308.

8 Case Record-13. N Engl F Med 1986; 314: 903-13. 